\title{
Glottic Cancer pT2 TNM Finding v6 and v7
}

National Cancer Institute

\section{Source}

National Cancer Institute. Glottic Cancer pT 2 TNM Finding v6 and v7. NCI Thesaurus.

Code C64676.

Glottic cancer with tumor extending to supraglottis and/or subglottis, and/or with impaired vocal cord mobility. (from AJCC 6th and 7th Eds.) 